\title{
Accident risk management strategy at un-signalized intersection
}

\author{
Don Gaspar Noesaku da Costa ${ }^{1, *}$, Siti Malkhamah², and Latif Budi Suparma² \\ ${ }^{1}$ Ph.D. student, Department of Civil and Environmental Engineering, Universitas Gadjah Mada Jl. Grafika No.2 55281 Yogyakarta, \\ Indonesia \\ ${ }^{2}$ Department of Civil and Environmental Engineering, Universitas Gadjah Mada Jl. Grafika No.2 55281 Yogyakarta, Indonesia
}

\begin{abstract}
The increasing of traffic sign and/or light violations is a commonly views in many countries. Even it was occurred intentionally which indicates that drivers accept its possible consequences. The constant fatality index of motorcyclist strongly indicates that determinant variables behind their risky behaviour and/or accident involvement should be further investigated and managed systematically. Accordingly, this paper focuses on motorcyclist accident risk management, particularly at un-signalized segment, by combining the aggregated-individual and expert expectancy approaches. Therefore a questionnaire and braking manoeuver test were undertaken at closed circuit course. The result shows that speeding behaviour was caused by trip purpose and triggered by perception about their braking and hazard detection abilities. In addition, only $24 \%$ of $56 \%$ of riders who believed that their braking capability was above average could apply high braking capability so that most riders might involve in crash due to the average critical crossing gap choice at the monitored intersection. This explains that their speed choice should be deal with their braking capability. However, the overlay policy at the monitored intersection indicates that the unbalanced between mobility and safety still to be a latent issue, which virtually could be bridged by using a standardized braking capability.
\end{abstract}

\section{Introduction}

A steady increase in traffic accident number and/or fatalities over the last 20 years triggered the United Nation's Decade of Action (DoA) on Road Safety 20112020. In addition, the fatality index was also relatively constant, not only in developing countries such as Indonesia [1], but also in developed countries [2]. It is thought that the high number of accident and the constant fatality index over the years is worth to be considered to be a disaster in transportation field so that a synchronized accident risk management strategy should be developed continuously, particularly at risky road segment areas such as un-signalized intersection, crossing lane, etc.

Intersection areas are commonly known to be one of the most vulnerable traffic accident segments due to insufficient braking capability [3], poor sight distance [4], traffic sign violations [5], speeding in the dilemma zone [6], etc. Therefore, the safety policy priority in some developed countries have been started with developing frontal and side impact regulation because these types of collision is the most common types [7].

Thus far, for road infrastructure design devices, the horizontal sight distance was more focused on various types of horizontal curve [4], whilst for intersection sight distance, it was determined based on geometrical aspects, including the availability of sufficient clearance area at the approaching lengths. Whereas, a number of accident at intersection occurred due to insufficient braking capability and/or inappropriate speed choices [3], particularly when the distance of crossing vehicle intended for entering or exiting a minor road (critical crossing gap acceptance) is too close with the major stream vehicle.

Further, although an intersection usually was completed with traffic sign that organize the speed limit and priority movement of minor and major stream, but major stream's drivers usually reluctant to give way for crossing vehicle; even, increase their vehicle speed. This infortune situation increase the delay time. Consequently, entering and/or exiting vehicle's driver became impatient and insisted to across the lane speculatively. In this particularly case, the distance between crossing and major stream vehicle is referred to as critical crossing gap acceptance (CGA) and defined to be the availability stopping sight distance (ASSD) [3].

Furthermore, exceed vehicle speed at the dilemma zone or amber light was also a commonly view, even in wet pavement conditions. Speeding (exceeding regulated speed limit and/or inappropriate speed choices (driving too fast for the prevailing conditions, but within the limits, [8]) $[9,10]$ ) was commonly accepted to be factor associated with accident occurrence and/or fatal accident. Since for avoid crash each rider needs adequate time and space to react and decelerate (brake) safely, it is thought that speed choice, insufficient reaction time and braking capability play important role in any type of accidents. Therefore, as speed choice usually influenced by rider's perception about their braking capability, whereas their perception could be wrong, it could be inferred that braking capability played very important role. In this particular case, riders should produce their minimum stopping sight distance (MSSD) which could only be achieved if the pavement surface is in good condition.

\footnotetext{
* Corresponding author: dnoesaku@gmail.com
} 
Accordingly, this paper focuses on how to develop an appropriate accident risk management strategy suited to driver expectancy (speed choice and determinant variables behind it) and road safety services (road pavement condition which is suited to various braking capabilities and/or speed choices), because the unbalanced in safety performance and mobility needs was a latent issue that should be bridge. Besides, this study also focuses on motorcyclist risk due to their index fatality tend to constant, not only in developing countries, such as Indonesia [1], but also in developed countries [2].

\section{Study Design}

The accident risk situation was monitored at one of the un-signalized intersection with high number of traffic accident at Yogyakarta, i.e. at, km.13 of Jl. Raya Solo, as can be seen in Figure 1.

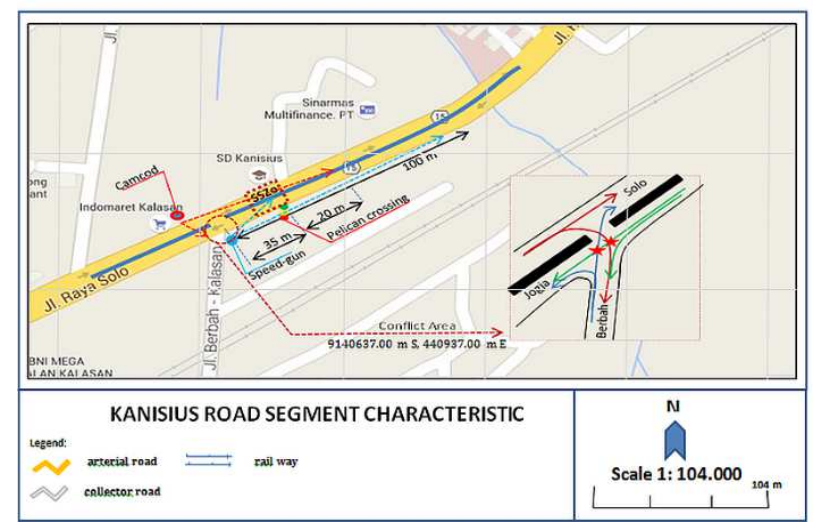

Fig. 1. Characteristic of study location.

Since the intersection was a point of conflict between major and minor road, a crossing conflict was the most potential type of accident due to high speed choice of major stream, in accord with the result of preliminary interview with surrounded local citizen.

Therefore, the major stream's initial and approaching speeds were measured using speed-gun. It was collected not only to identify whether they reduce their vehicle speed or not, but also to determine their engine and/or hard braking deceleration rates. However, such deceleration rate is difficult to be measured due to mixed traffic composition and high traffic volume or density.

Therefore, a braking manoeuver test was undertaken at closed circuit course, located around $3 \mathrm{~km}$ from that monitored intersection. The pavement condition at the closed circuit course and monitored intersection were relatively similar, i.e. level and good pavement surface condition (the skid resistance was around 60-67 and 5659 SRV respectively).

The braking manoeuver test was conducted in dry pavement condition because from speed measurement at the monitored intersection result it was found that motorcyclist speed choice was around $40-75 \mathrm{~km} / \mathrm{h}$. A previous study reported that in such vehicle speed choice, drivers could obtain their similar minimum braking distance both in wet and dry pavement conditions [11]
A number of 141 of volunteers haves been successfully recruited. Before participate, they were explained the aim and risk of this braking manoeuvre test, i.e. to identify their hard braking deceleration rate. They were asked to travel at their daily favoured speed and then apply their hard braking capability as soon as they recognized the presence of stop sign and completely stopped their vehicle before the flag sign position. During the test, their actual reaction time (the elapse time since the stop sign arose until their rear brake light was flashed), braking distance (the distance between the stop line and stopped vehicle), skidding distance (scratch viewed on pavement surface) were measured using camera recorder and visual observation. After that, they were asked to fulfil the questionnaire form which is intended to find out the difference between their perceptions about their braking capability with their actual hard braking deceleration rate, and the reason behind their daily favoured speed choices.

Previously, in order to obtain their engine braking deceleration rate, they were asked to travel with such speed choice and stop accelerate (downshift) when passing through the downshifting line. Therefore, their initial speed $\left(\mathrm{V}_{0}\right)$ and approaching speed $\left(\mathrm{V}_{1}\right)$ were measured using speed-gun.

Further, since before braking riders usually downshift instantly to reduce their vehicle speed, so that their reaction times were almost zero and the time needed since recognized the presence of hazardous object until they actually applied the brakes was referred to as reaction and downshifting time $(\mathrm{t})$. Hence, based on those obtained speeds, engine braking deceleration rate $\left(a_{1}\right)$, minimum reaction and downshifting time, and hard braking deceleration rate $\left(a_{2}\right)$, their minimum stopping sight distance (MSSD) were determined using the following Equation 1.

$$
\min S S D=V_{0} t-\frac{1}{2} a_{1} t^{2}+\frac{V_{1}^{2}}{2 a_{2}}
$$

Based on those MSSDs, their accident probability were predicted using the ratio of the available stopping sight distance (ASSD, which is equalled to the CGA at monitored intersection) to MSSD, defined as safety factor (SF). If the SF less than 1.0, then it means a crash might be occurred, as can be seen in Equation 2.

$$
S F=A S S D / M S S D \quad \geq 1.0
$$

Subsequently, the SFs was used to determine the margin of safety (MS) reflected the minimum effort required to avoid crash and/or fatal crash by using Equation 3.

$$
M S=S F-1
$$

Moreover, the determination of a proper MS was influenced by the tolerable accident consequence which could be predicted using impact speed. According to WHO the if the impact speed was $50 \mathrm{~km} / \mathrm{h}$ then the fatal crash probability for pedestrian, cyclist or motorcyclist was around $80 \%$ [9], whilst other researcher reported that the tolerable head injury criteria (HIC) was related to an 
impact speed of $43 \mathrm{~km} / \mathrm{h}$ [12]. In this particularly case, the impact speed $\left(\mathrm{V}_{2}\right)$ for various speed choices $\left(\mathrm{V}_{0}\right)$ and hard braking capabilities $\left(\mathrm{a}_{2}\right)$ at any predicted location of collision along the braking distance path (S) could be determined using Equation 4.

$$
S=\frac{V_{1}{ }^{2}-V_{2}{ }^{2}}{2 a_{2}}, \text { or } V_{2}=\sqrt{V_{1}{ }^{2}-2 a_{2} S}
$$

Accordingly, an appropriate accident risk management strategy should be built based on the tolerable accident consequence indicator.

\section{Results and discussions}

\subsection{Traffic and risk characteristics}

Form the result of traffic flow measurement at monitored intersection [3], it was found that: 1) the approaching speed was around $40-80 \mathrm{~km} / \mathrm{h}$ which much higher than the available regulated speed limit around the school safety zone (ZoSS), i.e. $25 \mathrm{~km} / \mathrm{h}$ 2) major stream's driver reluctant to give way to minor stream to across the intersection 3) the delay time to enter or exit the minor road is around 2 minutes occurred due to difference between major and minor stream volumes as well as high traffic density 4) since the delay time was felt too longer, driver who want to enter the minor road became impatient and insisted to across speculatively 5) when a driver started to across, another driver followed so that such crossing activities caused traffic delay due to weaving type of conflicts of the entering and exiting vehicles 6) vehicle that involved in traffic delays might be involved in crash if major stream's driver could not stop their vehicle suited to the ASSD created due to such critical crossing gap choices. These risky situations can be seen in Figure 2.

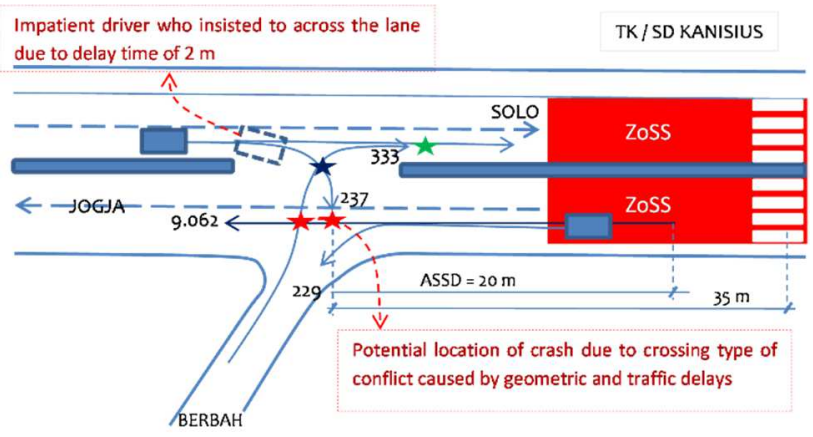

Fig. 2. Risky characteristic at the monitored intersection.

In this particularly case, in order to avoid crash, riders to apply their hard braking capabilities so that their produced MSSD could be shorter than the ASSD. Accordingly, from the result of braking manoeuvre test it was found that for a speed choice of $40-75 \mathrm{~km} / \mathrm{h}$, level 60-67 SRV pavement condition, the obtained hard braking capability could be classified into below average, moderate and above average categories, i.e. around 3.9 $\mathrm{m} / \mathrm{s}^{2}, 6.57 \mathrm{~m} / \mathrm{s}^{2}$ and $10.7 \mathrm{~m} / \mathrm{s}^{2}$ respectively. The below average braking deceleration rate is greater than
AASHTO's recommendation, i.e. $3.4 \mathrm{~m} / \mathrm{s}^{2}$ [4], whilst the average one is similar with some previous concerned studies, i.e. $5.65 \mathrm{~m} / \mathrm{s}^{2}$ [13] and $6.6 \mathrm{~m} / \mathrm{s}^{2}$ [14]. Interestingly, the above average braking deceleration rate of $10.7 \mathrm{~m} / \mathrm{s}^{2}$, which could be achieved by $24 \%$ or participant, is greater than both ABS motorcycle and passenger car braking deceleration rates, i.e. $7.72 \mathrm{~m} / \mathrm{s}^{2}$ [13] or $7.8 \mathrm{~m} / \mathrm{s}^{2}$ and 10 $\mathrm{m} / \mathrm{s}^{2}$ [14] respectively. It strongly indicates that accident probability and its potential consequence are much influenced by riders braking capability.

Further, the obtained minimum reaction and downshifting time was $0.53 \mathrm{~s}$, little shorter than similar previous related study finding, i.e. $0.68 \mathrm{~s}$ [15], whilst the average engine braking deceleration rate was around 1.29 $\mathrm{m} / \mathrm{s}^{2}$. This indicates that engine braking deceleration rate was influenced by speed choices, and may well also influenced by the air pressure of the tire and aerodynamically factors.

Therefore, based on when these various speed choices $(40-80 \mathrm{~km} / \mathrm{h})$, a reaction and downshifting time of $0.53 \mathrm{~s}$, and hard braking deceleration rates $\left(3.9 \mathrm{~m} / \mathrm{s}^{2}, 6.57 \mathrm{~m} / \mathrm{s}^{2}\right.$, and $\left.10.7 \mathrm{~m} / \mathrm{s}^{2}\right)$, as well as a CGA of $20 \mathrm{~m}$, the MSSDs, SFs and MSs could be calculated, as can be seen in Table 1.

Table 1. SF and MS for various speed choices and braking capabilities.

\begin{tabular}{|c|c|c|c|c|c|c|c|c|c|c|}
\hline \multicolumn{2}{|c|}{ Speed } & \multicolumn{3}{|c|}{ MSSDs* } & \multicolumn{3}{|c|}{ SF* } & \multicolumn{3}{|c|}{ MS* } \\
\hline$v_{0}$ & $v_{1}$ & 1 & 2 & 3 & 1 & 2 & 3 & 1 & 2 & 3 \\
\hline 80 & 75 & 71.9 & 49.1 & 36.2 & 0.28 & 0.41 & 0.55 & 0.72 & $\begin{array}{c}- \\
0.59\end{array}$ & $-\overline{4}$ \\
\hline 70 & 65 & 55.9 & 38.8 & 29.1 & 0.36 & 0.52 & 0.69 & $0 . \overline{6}$ & $0 . \overline{48}$ & $0 . \overline{3} 1$ \\
\hline 60 & 55 & 41.9 & 29.6 & 22.7 & 0.48 & 0.67 & 0.88 & 0.52 & 0.33 & 0.12 \\
\hline 50 & 45 & 29.9 & 21.7 & 17.1 & 0.67 & 0.92 & 1.17 & 0.33 & $\overline{0 .}$ & 0.17 \\
\hline 40 & 35 & 19.9 & 14.9 & 12.1 & 1.00 & 1.34 & 1.65 & 0.00 & 0.34 & 0.65 \\
\hline
\end{tabular}

$* 1=$ rider with below average braking capability; $2=$ moderate; $3=$ above average

It shows that the higher the braking capability, the shortest the produced MSSDs so that their avoidance crash probability more increase. In addition, only riders in moderate and above average braking capability categories could avoid crash if the speed choice was only $50 \mathrm{~km} / \mathrm{h}$ (the SF are nearly equal or $\geq 1.0$ ). It explains why a relatively high number of crossing conflicts have been occurred at the monitored intersection in this recent decade.

Moreover, from the MS value it could be inferred that riders in below average and moderate braking capabilities should increase their braking ability by up to $63.55 \%$ and $35.89 \%$ respectively. Such increasing values could be achieved because some previous concerned studies reported that it could be improved by using rear and front brakes consecutively and/or concurrently [16], where novice rider could increase their braking capability by $2.07 \mathrm{~m} / \mathrm{s}^{2}[13]$. 


\subsection{Risk analysis and its management strategy}

Since accident risk is also determined based on its possible consequence value, Figure 3 clearly shows that the predicted impact speed at a predicted location of collision along the braking distance path, so that the accident consequence probability could be determined using Figure 4.

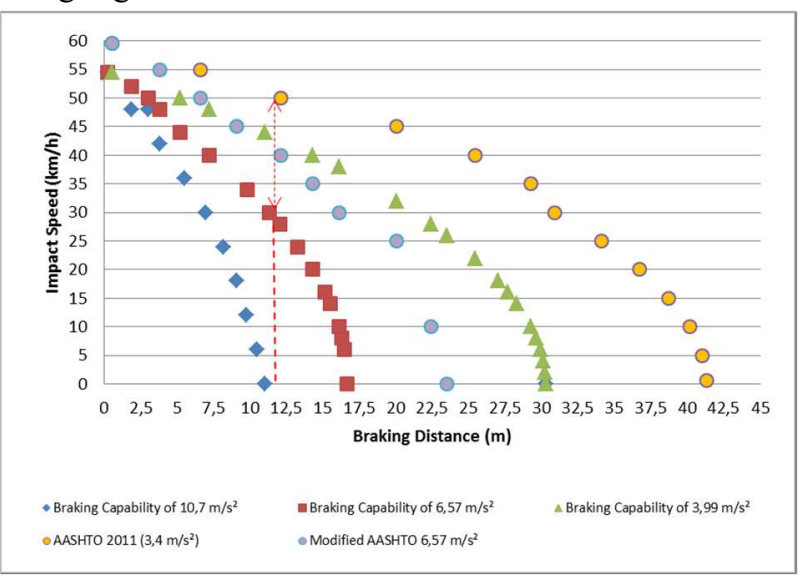

Fig. 3 Predicted impact speed along the braking distance path.

It can be seen that if the predicted location of collision was around $12.5 \mathrm{~m}$, the difference between riders in moderate braking capability categories' impact speed was around $12 \mathrm{~km} / \mathrm{h}$. hence, according to Figure4, such reduced impact speed could decrease fatal crash probability by up to $20 \%$. It should be noted that the braking deceleration rate obtained due to the pavement surface was in good performance (60-67 SRV). It means: 1) speed choice should be deal with braking capability 2) pavement surface should always be in well-preserved condition.

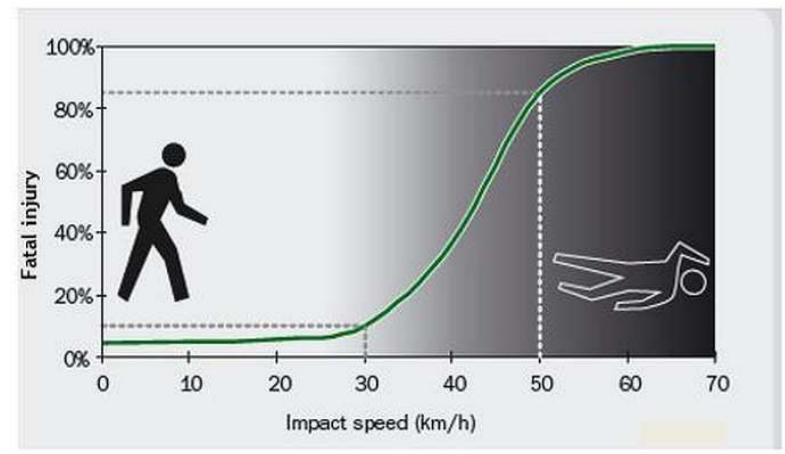

Fig. 4. Correlation between impact speed and fatal crash probability.

Therefore, the appropriate accident risk management strategy at the monitored intersection are:

1. The SRV value at all risky road segments such as un-signalized intersection zone, pedestrian crossing zone, etc. should be investigated and preserved regularly so that riders could apply their hard braking capability and produced their required MSSDs safely.

2. Riders braking deceleration rate should be increased and their speed choice should be deal with such braking capability. In this case, in order to bridge driver's mobility need, a standardized braking capability should be determined based on their daily favoured speed choices. This study found that it was around 6.57 $\mathrm{m} / \mathrm{s}^{2}$.

However, from the recent field observation conducted on march 2018 it was found that the safety school zone/ZoSS (Fig.2) was removed and relpaced with new pavement layer. This overlay policy strongly indicates that the road pavement condition was believed to be the primary factor associated with the current accident number. Although such preservation is required, it is noteworthy that without taking into acount the effect of driving capability such previous accident still could be ocurred because this study found that it was particularly much influenced by varying braking capabilities.

This finding strongly indicates that driving licensing mechanism should be improved, because the current driving licensing process (knowledge-training material and practical skill segments) in both developed and developing countries was more focused on driving manouver (including quick or hard braking manoeuver) capability [17-23], instead of how to riding safely and avoiding crash ability based on their produced braking capability. Riders has not been informed the consequences of their level of braking capability, particularly, in relationship with accident probability and/or consequences due to un-balanced between their braking capability and speed choice. Riders not only have to be able to apply hard braking manoeuver safely but also, particularly, recognise that their daily favoured speed should be dealed with their braking ability.

Consequently, in the near future, it is required further concerned studies which acommodate these following aspects: 1) the appropriate speed limit for higher speed choice on wet and dry pavement conditions 2) the establishment of long-life SRV values, particularly at any risky road segments.

It is hoped that by improving and applying such accident risk mitigation and/or management strategies, the number of accident and/or fatal index could be reduced significantly. In addition, the high number of traffic accident and its fatality index might be worth to be included in the term of disaster (referred to as « transportation disaster»).

\section{Conclusion}

The conclusion that could be drawn due to those previously descriptions and discussions are:

1. For speed choice of $40-60 \mathrm{~km} / \mathrm{h}$, braking distance was more influenced by braking capability instead of pavement condition (SRV), in accord with [11], so that all drivers should have a standardized braking capability, which might be obtained through the improvement of driving licensing mechanism, i.e. by adding the braking ability substance in the training material and practical skill segments, and, mostly, informed all riders about permitted speed choice suited to their braking abilities. 
2. Such braking capability could only be achieved when the pavement was in good condition so that it is required to monitor and well-preserved the SRV regularly, particularly at risky road segment such as un-signalized intersection.

3. As riders speed choices should be deal with their braking capability, hence the determination of speed limit should taking into account the effect of braking capability, and vice versa, riders should obey the regulated speed limit signs. In this particularly case, the law enforcement should also be improved.

4. Such strategies could produce optimum result if the effect of driver's motivation, perception and attitude are also taking into account properly, in accord with [24].

The authors would like to thank to the Indonesian Ministry of Research, Technology and Higher Education for research funding through "Hibah Penelitian Tim Pascasarjana" research grant scheme and also to Yayasan Pendidikan Katolik Arnoldus Kupang for "Studi Lanjut" relief fund.

\section{References}

1. D. G. N. da Costa, "Accident Risk Analysis of Motorcyclist," in 15th International Symposium of the Indonesian Inter University Transport Studies Forum (2012)

2. S. Joshi, T. Bellet, A. Banet, L. Robger, C. Turetscheck, R. Risser, J. Golias, G. Yannis, I. Spyropoulou, J. Carvalhais, L. Leden, J. Vasek, A. Delhaye, H. Robeboreck, G. Underwoord, and K. Humphrey, "Understanding risk taking behaviour within the context of PTW riders," Paris (2010)

3. D. G. N. da Costa, S. Malkhamah, and L. B. Suparma, "A Systematic Approach in Developing An Accident Risk Reduction Scheme," in 6th International Annual Engineering Seminar.ISBN 978-1-5090-0741-7, pp. 13-18 (2016)

4. AASHTO, A Policy on Geometric Design of Highways and Streets, 2011 6th E. Washington DC: American Association of State Highway and Transportation Officials (2011)

5. Y. O. Susilo, T. B. Joewono, and U. Vandebona, "Reasons underlying behaviour of motorcyclists disregarding traffic regulations in urban areas of Indonesia," Accid. Anal. Prev., vol. 75 (2015)

6. Y. Zhang, C. Fu, and L. Hu, "Yellow light dilemma zone researches: a review," J. Traffic Transp. Eng. (English Ed., vol. 1, no. 5, pp. 338352, Oct (2014)

7. S. P. Santosa, A. I. Mahyuddin, and F. G. Sunoto, "Anatomy of Injury Severity and Fatality in Indonesian Traffic Accidents," J. Eng. Technol. Sci., vol. 49, no. 3, pp. 412-422 (2017)

8. OEDC, SPEED MANAGEMENT. France: Transport Research Center (2006)

9. WHO, "Speed management: a road safety manual for decision-makers and practitioners.," Global Road Safety Partnership, Geneva, Switzerland (2008)
10. DaCoTA, "Speed and Speed Management," Deliverable $4.8 \mathrm{~s}$ of the EC FP7 project DaCoTA, www.dacota-project.eu (2013)

11. P. Cairney and A. Germanchev, "A pilot study of the effects of macrotexture on stopping distance" (2006)

12. S. Mihradi, H. Golfianto, A. I. Mahyudin, and T. Dirgantara, "Head Injury Analysis of Vehicle Occupant in Frontal Crash Simulation: Case Study of ITB 's Formula SAE Race Car,' J. Eng. Technol. Sci., vol. 49, no. 4, pp. 534-545 (2017)

13. M. Winkelbauer and K. Vavryn, "Braking Performance of Experienced and Novice Motorcycle Riders - Results of a Field Study," (2015)

14. NSW.Gov, "Motorcycle ABS," Road and Maritime Service. www.rms.nsw.gov.au (2012)

15. S. R. Davoodi, H. Hamid, M. Pazhouhanfar, and J. W. Muttart, "Motorcyclist perception response time in stopping sight distance situations," Saf. Sci., vol. 50, no. 3, pp. 371-377 (2012)

16. W. Bartlett, A. Baxter, and N. Robar, "Motorcycle Braking test: I.P.T.M. Data Through 2006," Accid. Reconstr. J., vol. July-Augus, no. ,pp. 19-21 (2007)

17. P. Woratanarat, A. Ingsathit, P. Chatchaipan, and P. Suriyawongpaisal, "Safety riding program and motorcycle-related injuries in Thailand," Accid. Anal. Prev., vol. 58, no. 2013, pp. 115-121 (2013)

18. Arizona Governor's Office of Highway Safety, An MSF Manual, Motorcycle Operator Manual, with supplementary information for three-wheel motorcycles (2016)

19. Swedish Transport Agency, Driving licence - do you know what applies? transportstyrelsen.se. (2017)

20. Idaho Transportation Department, Idaho Motorcycle Operator's Manual. Diviosion of Motor Vehicles. The Idaho Transportation Department Division of Motor Vehicles (2015)

21. M. Goodge, "Development of National Road Safety Strategy-Driver Training \& Licensing. Kiribati Road Rehabilitation Project, Ministry of Public Works and Utilities, Contract KRRP/C/4," November (2013)

22. Alberta Government, DRIVER' $S$ Guide to Operation, Safety and Licensing - Cars \& Light Trucks. www.transportation.alberta.ca (2013)

23. Florida Department of Highway Safety and Motor Vehicles, The Official Handbook-Florida Class E Driver License. A Safer Florida Highway Safety and Motor Vehicle (2017)

24. R. Hamidun, N. E. Kordi, I. R. Endut, S. Z. Ishak, M. Faudzi, and M. Yusoff, "Estimation of Illegal Crossing Accident Risk Using Stochastic Petri Nets," J. Eng. Sci. Technol., no. Special Issue on ACEE 2015 Conference, pp. 81-93 (2015) 